\title{
An immunization program against the COVID-19 infodemic
}

\section{Luis Claudio Correia' ${ }^{1}$ João de Deus Barreto Segundo² (1)}

${ }^{1}$ Corresponding author. Editor científico, Escola Bahiana de Medicina e Saúde Pública (Salvador). Bahia, Brazil. luisclcorreia@gmail.com 2Editor executivo, Escola Bahiana de Medicina e Saúde Pública (Salvador); Universidade Federal da Bahia (Salvador). Bahia, Brazil. jao.barreto@gmail.com

In the beginning of the current pandemic, we noted that several biomedical journals, regardless of tier and prestige, launched fast track sections open to articles related to the COVID-19 phenomenon. It is the purpose of science after all to find solutions to current emergencies and one could state at first that the effort was in itself altruistic, selfless and aimed to fulfill the scientific centuries-old promise of finding solutions to humanity's challenges ${ }^{\text {cf } 1-2}$.

At a closer look though, we have come to realize that a second epidemic took off along with the coronavirus dissemination: a publication epidemic, an infodemic. The team behind the Retraction Watch website were amongst the first to sound the alarm that the COVID-19 publication was moving at breakneck speed and that it could do more harm than good 3 and to this moment the Retraction Watch database has tracked around two dozens of retractions of pandemicrelated papers ${ }^{c f} 4$. It will be a few years though before being able to analyze the retraction rate of COVID-related papers 5 by means of comparing it with a control group. Yet, the time from article submission to online publication of COVID-related articles accelerated remarkably in comparison to previous publication timeframes according to independent studies published in pre-print servers and in prestigious journals as well $6-10$.

For example, two independent studies found that the median time to final acceptance was eight times faster for COVID-related articles as opposed to papers on other issues ${ }^{8-9}$. One of them found that the median time from article receipt to article being made available online was five times faster for COVID-related articles as opposed to papers on other issues and more than 10\% of COVIDrelated studies were found to had been accepted within two days after submission in a pool of PubMed-indexed journals which have had their metadata analyzed? .

The reporting of the same patients in different studies ${ }^{11}$ and the surge of duplicated (and poorly designed) clinical trials and systematic reviews ${ }^{12}$ resulted in an apocryphal paraphrase of the famous Douglas Altman line ${ }^{\text {cf } 13}$ making its rounds on Twitter stating that we need less COVID-19 research, better COVID-19 research, and COVID-19 research done for the right reasons ${ }^{14}$. 
We concur.

It appeared to be another highly contagious phenomenon of exponential growth: as one group of scientists published a fast tracked COVID-related article, other scientists developed a crave for rapidly publishing their own study and take part in the COVID-19 conversation, which made us wonder what the reproduction number of this infodemic would be.

During such a publication pandemic, there is not enough time for the germination of good ideas, a priori hypothesis conception, careful data analysis planning, which are the hallmarks of good quality research protocols. Thus, this current publication structure of incentives, being so avid for novelty and priority to foster professional careers but not necessarily scientific knowledge ${ }^{15}$, offer a high risk of confounding scientific news, that is, those studies that lower uncertainty regarding issues, with pseudonews, that is, wasteful studies that only fuel noise ${ }^{\text {cf } 12}$. In addition, a large quantity of publications about an issue may promote cognitive fatigue, robbing people of the time necessary to think about or digest the reading 15 . This maturation of ideas is especially pressing under the notion that low quality of evidence tends to mislead the readers. And it would appear that the COVID-related research is indeed of lower methodological quality in comparison with the standard of quality in which the medical journal ecosystem had been operating before the pandemics, which was in itself far from ideal .

As the biomedical community was developing its critical thinking skills during these past decades, the pandemic got us by surprise at a time we were not there yet. We were not sufficiently immunized against a dysfunctional ecosystem of sharing scientific information that values prestige, brand and citation over quality ${ }^{\text {cf }} 15-18$. The plethora of fast tracked publication easily becomes viral through social media and instant messaging apps. There is no social distance for this matter nor masks to mitigate the infodemic.

The team behind Evidence, the Journal of Evidencebased Healthcare, thought carefully about how to react to it. Firstly, we decided not to implement a call for articles regarding COVID-19. It would be a great opportunity to improve Evidence's citation activity but we do not want to be part of the problem, but part of the solution. Citation is not a sign of inherent quality, it is at best a sign of attention and trend ${ }^{c \text { 15-18. }}$. We decided it would be a terrible course of action to deviate from our main mission: to promote scientific integrity and robustness of evidence. So, we had no call, nor any fast track announcement. We opted for a more natural route of joining in the conversation, we were open to COVID-related papers but not calling for them. This course of action proved to be the best and most rational response to the crisis.

Although it was not our intention, the current issue ended up becoming a COVID-19 issue. It is very hard to avoid the topic these days after all. The Choosing Wisely International published the process and results of a "not to do" list regarding COVID-19 responses; the evidence-based medicine program of Escola Paulista de Medicina published a systematic review showing the lack of high quality evidence justifying hydroxychloroquine as COVID-19 treatment; and our research group on medical cognition published on the physician's preference towards this drug as COVID-19 treatment. As for concept articles, medical thinkers published their pieces on the issue of hydroxycloroquine, along with a thought experiment and two pieces on the bridging the gap section, that serves to translate the scientific philosophical and scientific reasoning to the public in general.

It is interesting to note that, although the prevalence of physicians in favor of hydroxycloroquine is high ${ }^{19}$, there was no concept article submitted to our journal offering high quality evidence to justify said drug as treatment for COVID-19. We keep expecting to receive high quality articles from those who argue for this as of yet non-evidence based therapy, clarifying the scientific rationale behind this preference. There is an educational value in weighing pros and cons.

At the final stages of issue preparation, we were under the impression that Evidence ended up being a provocative sample of the cognitive state of metascience and evidence-based medicine research communities during the initial months of this viral pandemic. Still, we must be aware of the risks of the infodemic leading into an irrationality pandemic because information overload does make true knowledge less accessible ${ }^{\text {f } 15}$. 


\section{References}

1. Pinto AV. Ciência e Existência: Problemas Filosóficos da Pesquisa Científica. Rio de Janeiro: Paz e Terra; 1979.

2. Merton RK. Ensaios de sociologia da ciência. São Paulo: Editora 34; 2013.

3. Marcus A, Oransky I. The Science of This Pandemic Is Moving at Dangerous Speeds. [Internet]. 2020. Disponível em: https:// www.wired.com/story/the-science-of-this-pandemic-is-moving-atdangerous-speeds/

4. Retraction Watch. Retracted coronavirus (COVID-19) papers. [Internet]. 2020. Disponível em: https://retractionwatch.com/ retracted-coronavirus-covid-19-papers/

5. Abritis A, Marcus A, Oransky I. An 'alarming' and 'exceptionally high' rate of COVID-19 retractions? Accountability in Research. 2020. doi: $10.1080 / 08989621.2020 .1793675$

6. Horbach SPJM. Pandemic Publishing: Medical journals strongly speed up their publication process for Covid-19. Quantitative Science Studies 2020: 1-16. doi: 10.1162/qss_a_00076

7. Helliwell JA, Bolton WS, Burke JR, Tiernan JP, Jayne DG, Chapman SJ. Global academic response to COVID - 19: Cross-sectional study. Learned Publishing. 2020. doi: 10.1002/leap.1317

8. Jung RG, Santo PD, Clifford C, Prosperi-Porta G, Skanes S, Hung A et al. Methodological Rigor in COVID-19 Clinical Research: A Systematic Review and Case-Control Analysis. medRxiv. 2020. doi: 10.1101/2020.07.02.20145102

9. Barakat AF, Shokr M, Ibrahim J, Mandrola J, Elgendy IY. Timeline from receipt to online publication of COVID-19 original research articles. medRxiv 2020.06.22.20137653. doi: 10.1101/2020.06.22.20137653
10. Palayew A, Norgaard O, Safreed-Harmon K, Andersen TH, Rasmussen LN, Lazarus JV. Pandemic publishing poses a new COVID-19 challenge. Nat Hum Behav. 2020. doi: 10.1038/s41562$\underline{020-0911-0}$

11. Bauchner H, Golub RM, Zylke J. Editorial Concern-Possible Reporting of the Same Patients With COVID-19 in Different Reports. JAMA. 2020;323(13):1256. doi: 10.1001/jama.2020.3980

12. Glasziou PP, Sanders S, Hoffmann T. Waste in covid-19 research. BMJ. 2020; 369:1847. doi: 10.1136/bmj.m1847

13. Altman DG. The scandal of poor medical research. BMJ. 1994;308:283. doi: 10.1136/bmj.308.6924.283

14. Smeden M. Twitter. [Internet]. 2020. Available at: twitter.com/ MaartenvSmeden/status/1249397761948164102

15. Génova G, Astudillo H, Fraga A. The Scientometric Bubble Considered Harmful. Sci Eng Ethics. 2016;22:227-235. doi: 10.1007/s11948-015-9632-6

16. Brembs B. Prestigious Science Journals Struggle to Reach Even Average Reliability. Front Hum Neurosci. 2018 12:37. doi: 10.3389/ fnhum.2018.00037

17. Dougherty M, Horne Z. Citation counts and journal impact factors do not capture research quality in the behavioral and brain sciences. PsyArXiv. 2019. doi:10.31234/osf.io/9g5wk

18. Merton RK. The Matthew Effect in Science. Science. 1968;159(3810):56-63. doi: 10.1126/science.159.3810.56. PMID 17737466

19. Correia LC, Lopes JRP, Garcez FB, Campion EL, Barcellos $\mathrm{G}$, Barreto-Filho JA. Physicians' preference towards the nonevidence based hydroxychloroquine treatment for COVID-19: the pandemic effect. J Évid-Based Healthc. 2020;2(1). doi: 10.17267/2675-021Xevidence.v2i1.3014 